\title{
INVENTION AND INTERPRETATION in Popular Music Historiography
}

\author{
Derek B. Scott
}

Invention in popular music historiography may be prompted by a desire to solve a problem, to provide a missing piece of a narrative, or to stimulate interest in a particular style or genre. Invention and interpretation often come together, as they did in the effort to establish the categories of »folk music « and »world music. "Sometimes the invention of one category necessitates the invention of another, as in the case of leichte Musik and ernste Musik. Many categories, including classifications of style and genre, are notoriously difficult to pin down. Genres keep breaking up into subgenres, and a musical style is subject to the tension between its conventions and the fingerprints of the individual artist. Frank Sinatra, for example, sings music of a certain style, but also sings in a certain (individual) style. This article scrutinizes examples of invention and interpretation, and speculates on the reasons why a historian or critic might take one or the other direction.

\section{Historiographical Inventions}

I begin with the eleven-line stave as an example of invention pure and simple. It served the purpose of explaining a baffling aspect of musical notation. A booklet published by the Associated Board of the Royal Schools of Music in 1958 states that the little line that is drawn through a note to indicate middle $C$ between the treble and bass staves »led many people to imagine that this little line was really part of the middle line of an elevenline stave, which they called the Great Stave (Rudiments and Theory of Music 1958: 18). The invention of the Great Stave was designed to resolve the puzzle about the lonely middle $\mathrm{C}$, stranded between two staves. The »many people« who were persuaded by the fiction of the Great Stave were presumably unaware that there existed clefs other than treble and bass (for 
example, the alto clef or the tenor clef). This is, of course, one of the dangers of coming to conclusions based on experience and observation. The curse of empirical research is to find that something turns up that the researcher was unaware of and which calls into question a supposed fact. Viola players were presumably never fooled because, for them, middle $C$ was placed right in the centre of the alto clef. ${ }^{1}$

Surprising as it may seem, music pedagogy appears unable to disentangle itself from invention. Popular last century in schools in England and Germany was the supposedly historic instrument, the recorder. Yet it was to large extent an invented instrument, because the recorder makers of neither country were consistent regarding its design. They were undecided about whether the model should be renaissance or baroque, and they were uncertain how far to incorporate modern features (there were plenty of plastic as well as wooden recorders). It is insufficient excuse to say that the instrument was merely a convenient means for pupils to learn about playing music and reading notation. In both countries it was wrapped up in so much more that was of historical and ideological importance. Nowadays, the ukulele is found increasingly in British schools. Once more, it is an easy instrument to begin to make music with, but again there is an ideological dimension. I should not allow myself to be side-tracked from my main topic, so I will content myself by saying that a ukulele sits uneasily with the traditional desire of schools to educate children about high culture. The change from recorder to ukulele takes place in the context of the postmodernist challenge to the binary opposition of high art and low art.

Sometimes, it is concepts that are invented. Examples are Light Music and Unterhaltungsmusik (or U-Musik). The reason these particular concepts were invented was because of the perceived need in an industrial and commercial age to filter out the trivial. Indeed, some musicologists preferred the term Trivialmusik (see the essays collected in Dahlhaus 1967). The trivial was deemed to bear the marks of commodification associated with industrial production, the »compulsion to mass produce and distribute commodities « (Dahlhaus 1989: 314). However, as already mentioned, the invention of leichte Musik necessitated, in turn, the invention of ernste Musik. Note that this is not a balanced binary opposition: it is not light and heavy, or easy and difficult; the »serious« is the ruling term, and »light «

1 The term »Great Stave « is still in use, although it now refers to the two staves bracketed together for keyboard instruments. In his Academic Manual of the Rudiments of Music, Augustus Holmes insists that an eleven-line stave was in use in "former times" (1949: 6). 
exists only in a negative and inferior relation to it. Serious music does not have to be difficult, but light music can never be serious.

There are whole categories of music that are invented for one reason or another. Sometimes a consensus builds up around what was at first a vague category, such as folk music. Dave Harker wrote at length in his book Fakesong (1985) about the folksong consensus that developed in England in the later nineteenth century and became well established in the next century (1985). He argued, as did Georgina Boyes in The Imaginary Village (1993), that the concept of the »folk « was in the main a useful fiction that served particular social, political, and cultural aims. There was also, however, an aesthetic dimension to the championing of a particular kind of song that was not linked to commodity production. The collector Cecil Sharp was clear about his enthusiasm for a type of song that might counter the appetite people had for music hall songs: »the mind that has been fed upon the pure melody of the folk will instinctively detect the poverty-stricken tunes of the music-hall, and refuse to be captivated and deluded by their superficial attractiveness« (Sharp 1907: 135). Classical music was thought too erudite for such minds, but the newly invented category of folk music offered a means of designating a type of music that was easy, that had the power to appeal to »the uncritical « (ibid.: 137), but was not contaminated by triteness. It could not be considered trite, because only music written for sale was perceived as trite.

What happened with folk music in England, happened in sometimes broader and sometimes narrower ways with various other musical categories. After the Gaelic League held their first ceilidh ${ }^{2}-$ which, with an element of prophecy, took place in England (London) rather than Ireland it was not long before an invented Celtic music came into existence. The instruments that began to be employed were enough to give pause to those seeking authenticity. They soon included the banjo and, in the 1970s, the bouzouki. Moreover, it was not necessary to have any familial or national Celtic identity to be part of the Celtic music scene. By the end of the twentieth century, there were Celtic music bands all over the world, just as there were Irish pubs (another invention) in cities around the globe. To single out one study related to this phenomenon, see Gordana Blagojević's article on Serbian »Irish « bands (2012). Another invented category of music worth briefly mentioning here is world music. The term was needed because record companies were seeking to market certain types of music that no longer fitted the labels used in record stores. It may seem, now, as if the

2 In Irish reformed spelling, céilí. 
world music section of a store consists simply of CDs stacked into partitions labelled with the name of a country, but it actually serves to suggest a particular type of music from that country. That is why you will discover that Austria's contribution to world music is zither melodies rather than the piano concertos of Mozart.

Musical genres can be invented, too. An example is $R \& B$ (rhythm and blues). From the 1920s on, some music had been released by record companies in the USA on »race records « (most notably by Okeh, Emerson, Victor, and Vocalion). Rather than being a reference to a musical genre (blues, jazz, or gospel), race records merely denoted that the performers were African American. The use of the term »race« was not considered derogatory at the time, but sensibilities and changing consumption patterns in the later 1940s required saying farewell to race records and hello to $R \& B$. Billboard magazine renamed its race records chart the rhythm and blues chart in 1949. The label now did suggest a genre, and yet, it meant that white performers who performed music that appeared to belong to this genre, for example, the songs of Jimmie Rodgers, and some of those of Bill Monroe (»In The Pines«) and Hank Williams (»Move It On Over«) could not appear in the $R \& B$ chart. Instead, they appeared in the country music chart. It was not long before another new genre, rock ' $n$ ' roll, was invented to indicate white $R \& B$. In the 1960 s, the focus shifted back once more to black performers rather than musical genre, when a new term was found to indicate music performed by African Americans, In this decade, soul music, although at first used to indicate a mixture of $R \& B$ and gospel, was to become a general catch-all term for black music-making ( $R \& B$, gospel, Motown, and funk).

\section{Some Concluding Thoughts on Invention}

Invention is often born of untested suppositions about music that spring from limited amounts of knowledge. In order to challenge such suppositions, perhaps a lead could be taken from the work of ethnographers. Kay Kaufman Shelemay suggests that an ethnographic model for music research allows the assumptions of scholarship to be tested and disputed; moreover, »ethnographic study of living traditions could both enhance the historical musicologists' appreciation of the workings of a fully contextualized music culture and expose the interaction between music and musicians (Shelemay 2001: 24). In a special issue of Ethnomusicology Forum dedicated to the ethnomusicology of Western art music, Laudan Nooshin stresses the 
value of »ethnographic methods (including participant observation) hitherto only rarely used within musicology« (Nooshin 2011: 297). Stephen Cottrell, in an ethnographic study of professional music-making in London, illustrates what is to be gained by such methods when he remarks:

»It seems unlikely that a performance of, say, Elgar's Pomp and Circumstance marches or Wagner's Siegfried can mean the same to audiences in London, Dresden, Delhi and Hong Kong, yet the readings of such works provided by musicologists usually assume that they do« (Cottrell 2004: 5).

Nooshin stresses that what is of paramount interest from an ethnomusicological perspective is »what music means to different people in different places« (Nooshin 2011: 297). This leads us neatly to questions of interpretation, and what validates or discredits an interpretation. To my mind, there is crucial distinction to be made between an interpretation that follows on from the assumption of the prior existence of a phenomenon, and an interpretation that explains a phenomenon that has been identified only after rigorous investigation.

\section{Interpretative Fallacies}

Music is often labelled so as to suggest it is characteristic of race rather than ethnic communities: we hear of Black music, Celtic music, and Gipsy music. This is what I refer to as a genetic interpretation. If you are a Gipsy, then Gipsy music is assumed to be in your flesh and blood - in your genes, no less. This belief is as naïve as the stale notion that black people have a natural sense of rhythm. It is nothing other than biological essentialism.

Labelling music in a manner that points to a gender distinction may, at first, seem more plausible. An example would be »cock rock « (Frith/ McRobbie 1978). The term was once thought useful for locating phallocentrism in music, but theory has moved on. Queer theory has challenged the idea that sexual identity, sexual behaviour, and gender are biologically determined. Instead, they are perceived as socially constructed and, therefore, mutable. As a consequence, human beings cannot be classified sexually in any stable and singular manner. The sexual identity a person has is the sexual identity that person performs and has learned to perform. The stumbling block for queer theory may be thought to be anatomical sex. However, we know how difficult it has been to determine anatomical sex in various sporting events. Even when parts of the anatomy can be pointed to as specifically relating to 
a male or female sex, there are other parts of the anatomy that are ambiguous. (Why do men have nipples, for example?)

The concept of cock rock did, of course, come under almost immediate attack for suggesting there was something male being expressed in the music, rather than a representation of masculinity constructed by the use of various musical devices. Queer theory goes further than this in challenging the idea that there can be any reliable sign of sexuality in music. A song full of conventions for signifying masculinity or femininity can be appropriated by the drag queen or drag king. A singer can also adopt multiple identities and use any number of different song styles to this effect. Moreover, this is not restricted to parody. A male singer may wish to sing a J udy Garland song with a sense of love and admiration for the song. And what if his performance strikes some people as camp? What if it is, indeed, camp? Again, queer theory has shown that gender and sexuality is nothing but performance. Camp is something performed, too, and through this performance a particular kind of sexuality is constructed. Asking whether or not this represents some form of genuine or false sexuality is as wrongheaded as asking if to be gay is natural or unnatural. Such categories are hors de combat in this argument. What does it mean to be authentically gay, lesbian, or bisexual? People used to think genuine English or Swiss folksongs existed. What are genuine gay songs?

We need to ask what connotes authenticity in any given style or genre, always bearing in mind that this authenticity or sincerity is performed, and sometimes this performance is repeated regularly on stage night after night. What are the signs of the authentic? I will give some examples of signs that create what I call the »authenticity effect « (in no particular order):

- A rough rather than polished performance (in Act 1 of Oscar Wilde's play The Importance of Being Earnest, Algernon boasts of his pianistic ability: »| don't play accurately - any one can play accurately - but I play with wonderful expression«)

- Lo-fi rather than hi-fi

- An ability to improvise (this technique offers a means of avoiding the »repetition of authenticity« problem)

- Acoustic rather than electric

- Simplicity rather than complexity (3 chords rather than 23)

- Old clothes and battered guitar rather than shiny suits and gleaming Gibson

- Staring at your shoes rather than at the audience

- Amateur rather than professional 
An interesting aspect of authenticity is the putting on of certain accents to sing songs. Why does a Welsh rock singer, singing in Welsh, feel the need to put on an American accent? Why did French singer J ohnny Halliday put on an American accent to sing French (and why was this a North American accent not a Canadian French accent)? Authenticity merges with masquerade in such performances.

\section{How Invention and Interpretative Fallacies Come Together}

If we focus on ideas of authenticity instead of reception - and the meaning popular music holds in the context of that reception - then we end up treating many consumers of popular music as dupes. There are many songs, for example, that have been mistakenly believed to originate in genuine expressions of community; yet, in the end, the mistake is of little importance. That is because it is the way music is used (or consumed) that gives it meaning. In Britain during the Second World War, for example, few people who listened to or joined in singing the song »There'll Be Bluebirds Over The White Cliffs Of Dover « paused to wonder why a non-native species of bird would be flying over those cliffs. The song served to bolster morale, and an ornithological error did not prevent it from being used in that fashion. Nor did it matter that its songwriters Walter Kent and Nat Burton were both American (although this explains why a mistake was made about British birds).

A song in the UK to which many would attribute a community origin is »Down At The Old Bull And Bush. «It is generally accepted as a genuine Cockney song, even if the Old Bull and Bush pub is in Hampstead Heath rather than in the Cockney East End of London, and the music hall singer who made it famous was Australian (Florrie Forde). It is sung to the following words:

Come, come, come and make eyes at me

Down at the Old Bull and Bush,

Da, da, da, da, da,

Come, come, drink some port wine with me,

Down at the Old Bull and Bush,

Hear the little German Band,

Da, di, da, di, da, dum, dum,

Just let me hold your hand dear,

Do, do come and have a drink or two 
Down at the Old Bull and Bush, Bush Bush.

Unfortunately, this turns out to be a type of popular song that is generally consigned to the scrap heap of despised, insincere, and inauthentic artistic products. Such derision is reserved for music created for blatantly commercial reasons, and this song was originally written as an advertising song for the Anheuser-Busch brewery in St Louis. The first recorded version was by Billy Murray in 1903, and was sung to these words:

Come, come, come and make eyes with me

Under the Anheuser bush

Come, come drink some >Budweis $<$ with me

Under the Anheuser bush

Hear the old German band... [accompaniment quotes opening of »Ach du lieber Augustin«]

Just let me hold your hand - ja-a!

Do, do come and have a stein or two

Under the Anheuser bush

There are, in addition, plenty of songs that are fully accepted by an ethnic group to which the songwriter does not belong, songs that have sometimes been created for no other reason than that there is a perceived market for them. An example is »The Rose of Tralee«, published in London around 1845-50, with Iyrics by C. Mordaunt Spencer, and music by Charles William Glover. The initial »C $C$ before the family name Mordaunt Spencer is probably given in error, and the author is almost certainly the London poet Edward Mordaunt Spencer. ${ }^{3}$ The composer, Charles Glover, was born in London and played the violin in orchestras at Covent Garden and Drury Lane theatres. The song soon took on a romantic life of its own, however, and became linked to actual events. It was said to have been written by a rich Protestant in love with a poor Catholic girl called Mary O'Connor. Today, it is even possible to visit her grave in Clogherbrien by taking the Fenit road out of Tralee - and you can bet it will have roses on it. A website promotes the Rose of Tralee competition which, since 1959, has been held in Tralee, County Kerry. ${ }^{4}$ Every year a young woman is declared to be the »rose. « To win, she has to be the one that most closely matches the description in the song - especially the bit about being »lovely and fair. «Furthermore, she

3 The Heir of Abbotsville and other poems were published by the author in London that year. The Rose of Tralee (words and music) appeared in the Book of Beauty for the Queen's Boudoir (London: C. J effreys, c. 1850), and here the Iyricist is given as E. Mordaunt Spencer.

4 http:// www.roseoftralee.ie: This website tells the tale of its being written by William Mulchinock for Mary O'Connor on its festival history page. 
needs to accommodate herself to a stereotypical Irish feature, and ensure she is »all smiling. " ${ }^{5}$ It is likely that this competition inspired the »lovely girls « competition that featured in an episode of the satirical TV comedy series Father Ted.

Sometimes the tune to a song is replaced, and later singers are unaware that they are no longer singing the original melody. An example is »Auld Lang Syne « by Robert Burns, which was based on J ames Watson's »Old Long Syne of 1711 (itself not original). Burns's rewritten song was published with its tune in the Scots Musical Museum in 1788. His version of the song is more Scottish in its vocabulary, a gesture of national pride that can be understood in the aftermath of the two defeats Scotland suffered at the hands of the English in the eighteenth-century. In spite of that, the tune that has been used since the nineteenth century resembles a melody in the overture of English composer William Shield's opera Rosina of 1781. It may be that this is a variant of an old tune that lies at the basis of both the current »Auld Lang Syne« tune and that of another traditional song »Comin' Through The Rye. «

\section{A clash of theoretical models}

I will conclude by illustrating problems of interpretation in writing popular music history with reference to some correspondence I had with Karl Gert zur Heide (2012: 9-17) on the origins of ragtime, which he locates in the Oriental rhythms heard at the Chicago World Fair of 1893.

For me, ragtime rhythms are syncopated, as were some early blackface minstrel songs and cakewalks. For him, rag melodies are not syncopated, but rhythmically asymmetrical, so minstrel songs and cakewalks are not ragtime precursors. He asked me to show him a cakewalk or song published before 1896 that persistently uses one of the two earliest rag patterns (in pulse notation: xxoxxoxx or xxoxxoxo). If I found one, he said he would acknowledge it as a rag precursor.

He was particularly convinced that the Arabic masmoudi rhythm (xxoxxoxx) inspired ragtime, so I referred him to an old minstrel song of the 1840s that used that rhythmic pattern.

5 It is a stereotype not limited to »When Irish Eyes Are Smiling, « the American song of 1912 with by lyrics by Chauncey Olcott and George Graff, J r., composed by Ernest Ball. 
Buffalo Gals won't you

come out tonight, won't you [xxoxxoxx]

come out tonight, won't you [xxoxxoxx]

come out tonight [xxoxxooo]

What is more, there is no accent on the syncopated note. It is not »come OUT tonight. «Thus, this type of syncopation distinct from the Beethoven type. Moreover, this non-accented syncopation is a feature of jazz and blues. Karl defined syncopation as »an occasional shift of accent, « but here there is no shift of accent, only the absence of a note on which an accent would be expected to fall.

His response was brief and dismissive: »Do you think it's possible that its prominent rhythm pattern (xxoxxoxx) inspired ragtime? I doubt it. « He informed me that the other common ragtime pattern xxoxxoxo also turns up before 1896, for example, in »Monsieur Banjo« (1867), but, again, he didn't think it led to the rag revolution of 1896 , although it might have paved the way.

I remained troubled by his definition of syncopation as well as by his neglect of clave rhythms. I wondered why no Latin or Caribbean music played a part in his theorizing. I wondered, too, whether he was oversimplifying some of the Arabic rhythms, like the masmoudi. There are many examples of musicians playing this rhythm on YouTube, and it seems reductive to define it as xxoxxoxx. What is conceived as awzān or wazn in Arabic music involves metre as well as the rhythm within the metrical unit (the bar, or measure, of music in Western terminology). The way the metrical unit is split can give rise to different rhythmic accentuations, but still be described as masmoudi (for example, it can begin with either two or three leading beats, and there can be subdivisions of beats).

We failed to reach any consensus about ragtime, and I found myself reflecting on our differences of interpretation. His stance, as I saw it, was that there was a pure ragtime and it had a specific origin. For me, classification is no simple matter and always involves some element of construction: do you classify with reference to similarities, for instance, or with reference to differences? We know the problems Linnaeus had classifying the seahorse, and we are familiar with the more recent debate about whether homo floriensis discovered in 2003 was a new species of human being. The problems in classifying culture and searching for origins are even more fraught with difficulty, and I see this activity myself as a fruitless pursuit. Think of the game Michel Foucault has with classifications in the preface of his Les Mots et les choses (1966). 
I have already mentioned the danger of relying solely on a collection of empirical data as evidence for declaring something to be a fact. J ust when there seems to be sufficient data to prove that all swans are white, along comes a black swan. Then you have to decide whether to reject what doesn't fit, or to reclassify your object of study. I continue to have some sympathy with Derrida's dictum that »empiricism is the matrix of all faults menacing a discourse « (Derrida 1978: 364). For this reason, Karl and I were unlikely ever to agree in our interpretations; in terms of cultural theory we were at polar extremes (his models being empirical and positivistic and my models being poststructuralist and social constructionist).

As it happens, I do see a song like »Buffalo Gals« as moving in a musical direction that relates to the development of ragtime. I was not able, either, to accept Karl's position on syncopation. Is an asymmetrical pattern never syncopation whatever the musical context? Karl hears ragtime as polyrhythmic rather than syncopated, but I hear it as syncopated. Something like the Charleston »Muskrat Ramble« as played by Louis Armstrong and his Hot Five would be polyrhythmic for me. I hear a much more consistent asymmetric pattern $(3+3+2)$ being played against a regular two-beat rhythm in that piece than I hear in a typical ragtime piece. I am not clear, either, how to explain in terms of Arabic rhythms the notes so frequently tied across the barline in ragtime, as happens, for example, in Scott Joplin's »Maple Leaf Rag« in the second half of the first section. I guess, in a polyrhythmic interpretation, none of these are heard as »pushed notes « in the jazz sense of that term. I leave aside the bigger questions of how Arabic music of the 1890s, being neither polyphonic nor polyrhythmic, became the source of any polyrhythms in ragtime.

I was interested in Karl's Chicago and New York perspective on ragtime, and I certainly would not cast doubt on the importance of developments in New York in the mid-1890s, but I still think he needed to do more to explain away developments in New Orleans, St Louis, and perhaps other cities. We know little about how some of the late nineteenth-century New Orleans bands played. There have been efforts to reconstruct the sound of Buddy Bolden's band, ${ }^{6}$ but what about others, such as Stalebread's Razzy Dazzy Spasm Band of the 1890s? Beyond this, we need to investigate the role that might have been played by African-Caribbean rhythms that had been known since the late eighteenth century, such as the amphibrach (Manuel 2009: 20-21). The amphibrach pattern, which is identical to one of the two earliest rag patterns (xxoxxoxo), is given a Congolese origin by ethno-

6 For instance, by British jazz trumpeter Humphrey Lyttelton in 1986; see YouTube: www. youtube.com/ watch?v=x5tZcwmw8M4. See also Hardie 2007. 
musicologist Peter Manuel (2009: 69). It is also tempting to point out that systematic polyrhythms (otherwise known as cross rhythms) are a feature of Sub-Saharan African music.

The purpose of my going into detail about this argument about the origin of ragtime is to illustrate how two conflicting theoretical models or paradigms of thought can produce two interpretations that share very little in common. This is a moment when Lyotard's concept of the différend (1983) begins to haunt historiographic interpretation. There are times when a dispute cannot reach consensus, because the discourse employed by each party is incompatible and allows no settlement. I argue, however, that we should always acknowledge any quandary (or aporia) we encounter, and raise awareness that historiography deals with confusion as well as elucidation.

So, to conclude: what would I regard as an example of a useful or helpful interpretation that avoids some of the pitfalls I've been discussing in this essay? I'll pick up on the term »global fusion. "Why is there a need for this term? It is because of a desire to name what is happening in electronic dance music in clubs around the world; it usefully identifies the complex sampling and mixing of styles by DJ s. In other words, it arises from a desire to name an observable phenomenon. I probably repeat myself here by insisting that it is crucial that the observation or discovery of the phenomenon should come first, and only then should the scholar attempt to identify and name it. A term I've mentioned previously, »world music, « came about under very different circumstances. Record companies saw an opportunity to sell recordings of popular music genres from around the world - actually, mainly from Africa - and their marketing teams needed to find a term for this music in the same way that other businesses seek labels to brand their commodities.

Nevertheless, useful as the term »global fusion « may be for identifying a phenomenon, it still requires interpretation. It draws our attention to certain musical practices that we need to understand technically, and what they mean socially. For me, global fusion represents a kind of music that mixes different musical cultures and traditions in way that challenges some aspects of postcolonial theory, such as cultural mixtures that constitute a politically charged hybridity. Suddenly, there appears to be no friction in the mix, no »ruse of recognition « as Homi Bhabha (1994: 165) puts it: there are layers of sampled elements, or there is a mosaic of cultural references. The challenge for cultural sociology and musicology now is to offer an interpretation of its meaning. 


\section{Bibliography}

Bhabha, Homi (1994). The Location of Culture. Abingdon: Routledge.

Blagojević, Gordana (2008). »Folklore Music in a Global Village: >Irish Serbs in Belgrade Today. «In: Musical Folklore as a Vehicle? Ed. by Mirjana VeselinovicHofman. Belgrade: Serbian Musicological Society / International Musicological Society, pp. 107-112.

Boyes, Georgina (1993). The Imagined Village: Culture, ideology and the English Folk Revival. Manchester: Manchester University Press (revised edition London: No Masters Cooperative Limited 2010).

Cottrell, Stephen (2004). Professional Music-making in London: Ethnography and Experience. Aldershot: Ashgate.

Dahlhaus, Carl (1989). Nineteenth-Century Music. Trans. J. Bradford Robinson. Berkeley, LA: University of California Press (orig. pub. as Die Musik des 19. J ahrhunderts. Wiesbaden: Athenaion 1980).

Dahlhaus, Carl (Ed.) (1967). Studien zur Trivialmusik des 19. J ahrhunderts. Regensburg: Gustav Bosse.

Derrida, J acques (1978). „Structure, Sign, and Play in the Discourse of the Human Sciences. «In: Jacques Derrida, Writing and Difference. Trans. Alan Bass. London: Routledge, pp. 351-70.

Foucault, Michel (1966). Les Mots et les choses: Une archéologie des sciences humaines. Paris: Editions Gallimard.

Frith, Simon / McRobbie, Angela (1978). »Rock and Sexuality. «In: Screen Education 29, pp. 3-19 (reprinted in Simon Frith / Andrew Goodwin (Eds.) (1990). On Record: Rock, Pop, and the Written Word. London: Routledge, pp. 371-89; excerpted in Derek B. Scott (Ed.) (2000). Music, Culture, and Society: A Reader. Oxford: Oxford University Press, pp. 65-70).

Hardie, Daniel (2007). The Birth of J azz: Reviving the Music of the Bolden Era. Bloomington, IN: iUniverse.

Harker, Dave (1985). Fakesong: The Manufacture of British Folk Song, 1700 to the Present Day. Milton Keynes: Open University Press.

Holmes, G. Augustus (1949). Academic Manual of the Rudiments of Music. London: A. Weekes.

Lyotard, J ean-François (1983). Le Différend. Paris: Editions de Minuit.

Manuel, Peter (2009). »Introduction. «In: Creolizing Contradance in the Caribbean. Ed. by Peter Manuel. Philadelphia, PA: Temple University Press, pp. 1-50.

Nooshin, Laudan (2011). »Introduction to the Special Issue: The Ethnomusicology of Western Art Music. « In: Ethnomusicology Forum 20:3, pp. 285-300.

Rudiments and Theory of Music (1958). London: Associated Board of the Royal Schools of Music.

Sharp, Cecil J . (1907). English Folk-Song: Some Conclusions. London: Simpkin jointly with Novello.

Shelemay, Kay Kaufman (2001). »Toward an Ethnomusicology of the Early Music Movement: Thoughts on Bridging Discipines and Musical Worlds. «In: Ethnomusicology 45:1, pp. 1-29.

zur Heide, Karl Gert (2012). »Origin of the Rag Time - Part 1. «In: Doctor J azz Magazine, No. 218 (Sep.), pp. 9-17. 


\begin{abstract}
Invention in popular music historiography may be prompted by a desire to solve a problem, to provide a missing piece of a narrative, or to stimulate interest in a particular style or genre. Invention and interpretation often come together, as happened in the effort to establish the categories of »folk music « and »world music. "Sometimes the invention of one category necessitates the invention of another, as in the case of leichte Musik and ernste Musik. Many categories, including classifications of style and genre, are notoriously difficult to pin down. Genres keep breaking up into subgenres, and a musical style is subject to the tension between its conventions and the fingerprints of the individual artist. This article scrutinizes examples of invention and interpretation, and speculates on the reasons why a historian or critic might take one or the other direction. I draw examples, for the most part, from historical and anthropological assertions regarding ethnicity, class, and gender in the production and consumption of popular music. Invention may be simply guesswork, or it may be a means of giving substance to a prejudice. It is important to distinguish between the imposition of pre-existing ideas and the effort to interpret identifiable musical phenomena. I argue that we should always acknowledge any quandary (aporia) we encounter, and raise awareness that historiography deals with confusion as well as elucidation.
\end{abstract}

